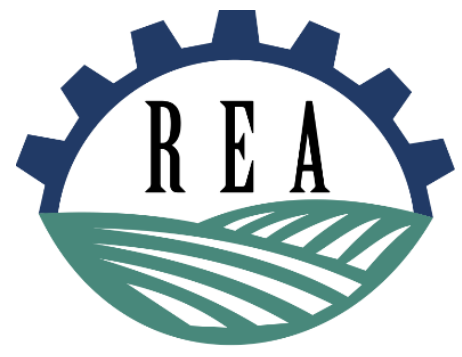

Revista de Economia e Agronegócio - REA ISSN impresso: 1679-1614

ISSN online: $2526-5539$

Vol. 15 | N. 2 | 2017

\section{É A ÍNDIA UM MERCADO RELEVANTE PARA AS EXPORTAÇÕES AGROPECUÁRIAS BRASILEIRAS?}

\section{RESUMO}

O objetivo deste estudo é analisar a concentração das exportações agropecuárias brasileiras em torno do mercado importador da Índia. Para tal, foi estruturada uma série de 27 anos (1989-2015) de exportações agropecuárias Brasil-Índia. Os procedimentos metodológicos consistem do Quociente Locacional (QL), do Coeficiente de Gini Locacional (CGL) e do índice de HirschmanHerfindahl modificado ( $\mathrm{HHm})$. Igualmente, averiguou-se uma tendência com base no tempo ao longo do período investigado. Os resultados evidenciaram leve aumento de concentração dos produtos brasileiros em torno do mercado indiano até 2005, com perda de força do fenômeno a partir de então. Produtos para os quais a Índia exerce uma demanda líquida destacável também foram mapeados. Questões para aprofundamento são sugeridas em termos dos bens de demanda líquida identificada e em função dos potenciais que a Índia guarda com relação à demanda internacional de alimentos.

Palavras-chave: Agricultura; Exportações; Gini; Brasil; Índia.

\section{ABSTRACT}

The study aims to amount the Brazilian agricultural exports concentration around India. For doing so, it constructs a 1989-2015 series of Brazilian agricultural exports destined to India according to the Agricultural Agreement. Methodological proceedings include Locational Quotient (LQ), Locational Gini Coefficient (LGC) and Hirschman-Herfindahl modified Index (HHmI). Moreover, it investigates a time trend for the LGC calculated data. Results showed a slight concentration of Brazilian agricultural exports around India up to 2005, but this phenomenon weakened from then on. The results also detected groups of products in which a typical India's net demand happens. Further researches are suggested specially in terms of India's potential as a demander in world food markets.

Keywords: Agriculture; Exports; Gini; Brazil; India.

JEL Code: . 


\section{INTRODUÇÃO}

Nos últimos vinte anos, o Brasil tem ganho espaço na produção de alimentos, com reflexos tanto no maior suprimento da demanda local por oferta doméstica quanto na geração de excedentes exportáveis. Há mais de quarenta anos, Bonelli e Malan (1976) afirmavam que a capacidade de gerar divisas cambiais por meio de exportações é tão crucial quanto a capacidade de poupá-las com base na substituição de importações.

Neste contexto, certos parceiros comerciais se notabilizam como destino tradicional das exportações agropecuárias brasileiras, como a União Europeia e os países do Oriente Médio, além do recente aumento de embarques com destino à China.

Em números agregados, a agricultura brasileira, aqui entendida como agropecuária e seus processados, expandiu sua participação no total de divisas auferidas pelo setor exportador brasileiro. Sob tal cenário, entre 1989 e 2015, a agricultura brasileira respondeu por contínuos superávits comerciais, representando hoje a terça parte das receitas de exportações totais do país (FREITAS, 2016).

Conforme Yokota (2002) e Barros e Barros (2005), são muitos e interligados os fatores por detrás desses resultados. Esse sucesso não se deve apenas a ganhos de produtividade e acesso a novas tecnologias, mas também a conhecidas vantagens comparativas do Brasil nessa área (relativa disponibilidade de terra, condições favoráveis de solos, água e clima, mão de obra ainda abundante) como atestado por diversos trabalhos (SOUZA et al., 2012; CÂMARA et al., 2015; FREITAS; MENDONÇA, 2016).

Todavia, é importante a descoberta e a entrada em mercados além dos tradicionais importadores de alimentos. Nenhuma estratégia comercial pode hoje prescindir da ampliação de parceiros comerciais. Assim, o objetivo deste trabalho é avaliar a concentração de exportações agropecuárias brasileiras em torno do mercado indiano. Como questão derivada, dado o perfil comprador da Índia, discute-se quais produtos têm sido mais demandados por aquele país.

A escolha do mercado indiano ancora-se em seu aspecto potencial, em termos da demanda por itens alimentícios. O país deve ultrapassar a China em termos de população total já na próxima década. Além disso, outros analistas já haviam ressaltado o caráter estratégico daquele país no segmento de lácteos (SANTO, 2010; NOGUEIRA, 2014), uvas frescas (FONSECA; XAVIER; COSTA, 2010), açúcares (SOUSA et al., 2011) e para os agrícolas brasileiros como um todo (SANTO; LIMA; SOUZA, 2012). O próprio ex-Ministro das Relações Exteriores, José Serra, destacara:

"É um comércio que pode ser muito maior do que tem sido, com um potencial enorme, e que pode ser duplicado, até triplicado ao longo dos anos. A India tem um grande potencial para investimentos agrícolas em matéria de alimentos, 
processos, refrigeração e de importação em si mesmo. É uma boa área para o Brasil, para vender e para investir". (BRASIL, 2016a)

Isto posto, o trabalho está organizado em quatro seções adicionais a esta introdução. A seção 2 apresenta o potencial indiano como fonte de demanda internacional por alimentos. A terceira seção apresenta a metodologia e as fontes de dados presentes no trabalho. Já as seções 4 e 5 trazem, respectivamente, a discussão dos resultados e as considerações finais.

\section{DEMANDA POR ALIMENTOS NO CONTEXTO INDIANO}

Inúmeros são os trabalhos (DA MATA; FREITAS, 2008; FONSECA; XAVIER; COSTA, 2010; SANTO; LIMA; SOUZA, 2012) que destacam as variáveis tamanho econômico e tamanho da população na explicação das exportações de bens agroindustriais.

O século XXI tem presenciado um grande dinamismo econômico e importador dos mercados asiáticos. Naquela região, projeções da Organização das Nações Unidas (UN, 2017) sinalizam que já em 2024 a população indiana ultrapassará a da China, o que tornará a Índia o maior mercado nacional em número absoluto de consumidores.

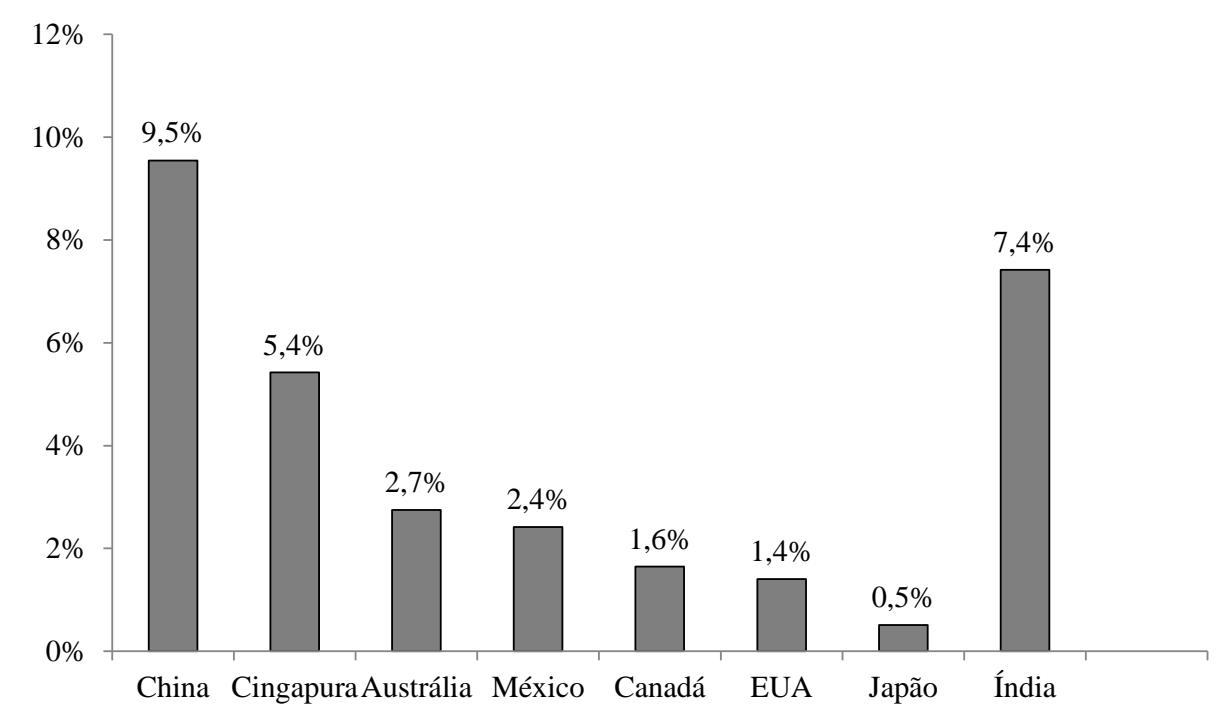

Figura 1. Crescimento real (US\$ de 2010) anual do PIB a preços de mercado, 2006-2015.

Fonte: Elaborado pelo autor com base em World Bank (2016).

O mercado indiano também se destaca no que toca ao seu dinamismo econômico recente. De acordo com a Figura 1, comparado com países 
relevantes na área do Pacífico, o crescimento real do PIB da Índia foi significativo entre 2006 e 2015, superando o desempenho de países como EUA, Austrália e Canadá.

No que pertence às políticas comerciais, conforme Santo, Lima e Souza (2012), trata-se de um país não disposto a abrir mão de seus mercados internos, praticando tarifas médias superiores a $37 \%$ em bens agropecuários, patamar relativamente alto em comparação com aquele verificado em outros mercados relevantes para o Brasil. Severas limitações burocráticas de acesso ao mercado local e pesada regulamentação sanitária sobre importações agropecuárias foram também detectadas por esses autores.

Além disso, o país implementa um amplo espectro de políticas setoriais voltadas para a agropecuária (WTO, 2015). Entre elas, incluem-se planos quinquenais de planejamento da política agrícola interna ${ }^{1}$, tarifas médias de importação de 36,4\% para bens agropecuários no biênio 2014-2015, presença de escalada tarifária, sistema de quotas tarifárias com significativo grau de burocracia para acesso e fruição por parceiros comerciais e intensa regulamentação sanitária sobre a importação de produtos de origem animal e vegetal.

\section{METODOLOGIA E FONTES DE DADOS}

O estudo contemplou dados sobre exportações brasileiras do BRASIL (2016b) no período de 1989 a 2015, compreendendo um período de 27 anos. A definição de produto agropecuário empregada é a descrita no Acordo Agrícola e obedeceu à WTO (2011). Desta forma, os itens do Sistema Harmonizado $(\mathrm{SH})$ de Classificação de Mercadorias correspondentes às exportações agropecuárias são aqueles apresentados na Tabela 1.

De modo a tornar compatíveis os itens da Nomenclatura Brasileira de Mercadorias (NBM) (1989-1996) e da Nomenclatura Comum do Mercosul (NCM) (1996-2015), fez-se necessária uma compatibilização metodológica das alíneas comerciais brasileiras em linha com BRASIL (1996). Para mais informações, esses procedimentos estão dispostos no Anexo do estudo.

A abordagem metodológica utilizou-se do Quociente Locacional (QL) e do Coeficiente de Gini Locacional (CGL). Na linha proposta por Crocco et al. (2006), essas ferramentas foram complementadas pelo índice de Hirschman-Herfindahl modificado (HHm). Ademais, aferiu-se a

\footnotetext{
${ }^{1}$ Neste leque, há que destacar programas domésticos de suporte de preços aos produtores locais, sobretudo em cereais, leguminosas, açúcar e juta, programas de crédito e seguro agrícolas, programas de apoio à aquisição de insumos e variados mecanismos e órgãos estatais de regulação de estoques de bens agropecuários (WTO, 2015, pp.101-104). 
significância estatística da tendência temporal do CGL com base na tabela de Analysis of Variance (ANOVA) (SARTORIS, 2003; GUJARATI, 1995).

\section{Tabela 1. Códigos SH do Acordo Agrícola}

\begin{tabular}{cc}
\hline Capítulo SH & Item \\
\hline 1 e 2 & Todos \\
4 a 24 & Todos (exceto peixes e suas preparações) \\
29 & 2905.43 e 2905.44 \\
33 & 33.01 \\
35 & 35.01 a 35.05 \\
38 & 3809.10 e 3823.60 \\
41 & 41.01 a 41.03 \\
43 & 43.01 \\
50 & 50.01 a 50.03 \\
51 & 51.01 a 51.03 \\
52 & 52.01 a 52.03 \\
53 & 53.01 a 53.02 \\
\hline
\end{tabular}

Fonte: Elaborado pelo autor com base em WTO (2011).

O QL e o CGL são desenvolvidos na subseção 3.1, ao passo que a subseção 3.2 detalha os procedimentos para cálculo do HHm e da tabela ANOVA.

\section{Quociente locacional (QL) e coeficiente de Gini locacional (CGL)}

Ambas as ferramentas têm sido utilizadas de forma ampla em estudos econômicos, com aplicação além da agropecuária e dos fluxos comerciais. Uma aplicação clássica dessa metodologia está em Krugman (1991), que avaliou a dinâmica locacional dos setores produtivos nos EUA.

A posteriori, o caráter flexível de uso dos indicadores foi demonstrado em suas várias aplicações por Lu, Flegg e Deng (2011), em estudos de especialização regional na China, por Ruan e Zhang (2014), em mapeamentos de realocações industriais, ou ainda, por Reveiu e Dardala (2011), que os utilizaram para diagnósticos de emprego e desemprego em municípios da Romênia.

O QL informará se a importância relativa da Índia é maior para um grupo $i$ de exportações agropecuárias brasileiras do que para todas as exportações (agropecuárias e não agropecuárias) brasileiras. Sob o prisma operacional, é um passo inicial para calcular o CGL, que, por seu turno, é útil para avaliar a concentração espacial de um grupo de exportações em um dado mercado comprador, a Índia, no caso em tela.

A equação (1) informa o QL, definido para cada grupo $i$ das exportações agropecuárias brasileiras de acordo com a definição de Haddad (1989): 
$Q L_{i j}=\left(X_{i j} / X_{i^{*}}\right) /\left(X_{* j} / X_{* *}\right)$,

em que:

$X_{i j}=$ exportações agropecuárias brasileiras do grupo $i$ para o país $j ; j$ : Índia, neste caso;

$X_{i^{*}}=$ exportações agropecuárias brasileiras do grupo $i$ para todos os países;

$X_{* j}=$ exportações brasileiras para o país $j ; j$ : Índia, neste caso;

$X_{* *}=$ exportações brasileiras para todos os países;

$\left(X_{i j} / X_{i^{*}}\right)=$ importância relativa da Índia nas exportações agropecuárias do Brasil no grupo $i$; e

$\left(X_{* j} / X_{* *}\right)=$ importância relativa da Índia nas exportações brasileiras totais (agropecuárias e não agropecuárias).

Em se tratando de amplos mercados importadores, como os mercados indianos importadores de alimentos, o primeiro procedimento é organizálos em ordem decrescente do QL, segundo uma variável selecionada, por exemplo, a parcela devida ao grupo $i$ nas receitas de exportações agropecuárias brasileiras. No estágio seguinte, constrói-se uma curva de localização para cada um dos grupos de produtos importados (mercados importadores) e então são definidos os pontos geradores da curva requerida, como a seguir definido:

i. As coordenadas de $Y$ são obtidas das proporções acumuladas da variável selecionada (a parcela devida ao grupo $i$ nas receitas de exportações agropecuárias brasileiras, por exemplo) no mercado de destino sob análise;

ii. As coordenadas de $\mathrm{X}$ são derivadas das proporções acumuladas da mesma variável (a parcela devida ao grupo $i$ nas receitas de exportações agropecuárias brasileiras) no mercado mundial, isto é, observando como destino todos os países do Mundo.

Tanto em relação às coordenadas $X$ como $Y$, a ordem em que os dados são imputados é dada pela ordem descendente dos QL. No hipotético caso de 5 grupos de produtos agropecuários brasileiros exportados, a curva final contemplaria 5 pontos, como na Figura 2.

O CGL é resultado da razão entre a área sombreada dada por $\beta$ (acima) e a área do triângulo $\mathrm{ABC}$, que é limitado por uma reta de $45^{\circ}$. Dessa maneira: 


$$
C G L=(\beta / 0.5)=2 . \beta
$$

O limite máximo do CGL é 1 , por ser o valor máximo de $\beta$ 0,50. Contudo, deve ser observado que nessa construção eventualmente $\beta$ pode assumir valores negativos. Os valores negativos ocorrem quando a área sombreada (dada por $\beta$ acima) gera pontos abaixo da reta de $45^{\circ}$. Nesse contexto, as proporções acumuladas nas coordenadas de Y (exportações brasileiras para a Índia ao longo dos grupos de produtos agropecuários) estariam abaixo das proporções acumuladas nas coordenadas de X (exportações brasileiras para o Mundo ao longo dos grupos de produtos agropecuários).

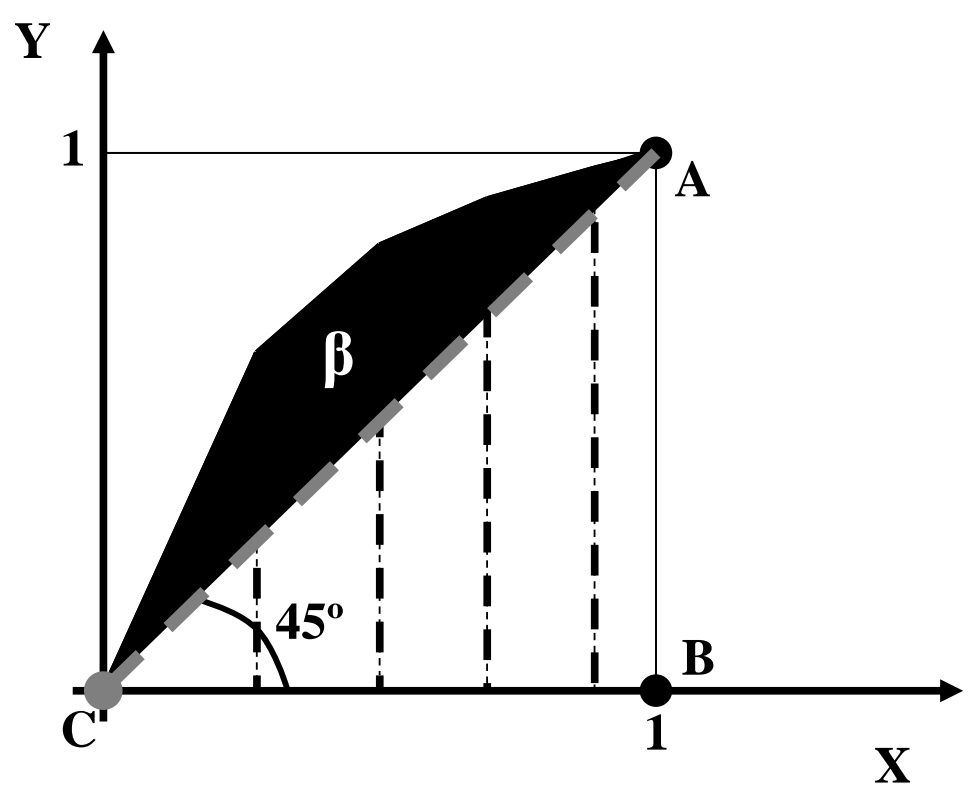

Figura 2. Área de concentração do CGL.

Fonte: Elaborado pelo autor com base em Krugman (1991) e Suzigan et al. (2003).

Quando isso se verifica, dada a pauta brasileira de exportações agropecuárias para o Mundo e para a Îndia, as coordenadas $(X, Y)$ acima definidas, são tais que, naquele ano em particular, o mercado indiano desconcentrou exportações agropecuárias brasileiras relativamente, tomando o conjunto de produtos agropecuários exportados.

Conforme argumento de Suzigan et al. (2003), quanto mais próximo de 1 o CGL, mais concentradas seriam as exportações agropecuárias brasileiras no mercado em questão e vice-versa. Todavia, no âmbito de um amplo mercado para importações agropecuárias, caso das compras internacionais de alimentos, o CGL tende a ser relativamente pequeno em função das dimensões de cada grupo $i$ de produto agropecuário mundialmente negociado. 


\section{Anova e demanda líquida por exportações agropecuárias brasileiras}

Uma vez estimado o CGL para o período de 1989 a 2015, pode-se analisar a tendência da série em termos de sua magnitude e significância estatística. Destarte, empregou-se o procedimento sumarizado na tabela ANOVA e o correspondente teste F. De acordo com Gujarati (1995) e Sartoris (2003), o teste F permite testar a hipótese de que a tendência da série seja nula. Desta forma, é possível aferir se, caso exista, a concentração (ou desconcentração) de exportações agropecuárias brasileiras em torno da Índia é consistente ao longo do tempo.

Para o âmbito deste estudo, parte-se de um modelo de regressão linear simples, utilizando o tempo (T) como variável explicativa do comportamento do CGL ao longo da série, conforme descrito na equação (3), em que o termo $u_{t}$ é assumido com as hipóteses clássicas acerca do comportamento do resíduo no modelo de regressão linear simples.

$$
C G L_{t}=\beta_{0}+\beta_{1} \cdot T+u_{t}
$$

No contexto da equação acima, Sartoris (2003) desagrega a variância total observada (SQT) em variância devida ao modelo linear simples (SQReg) e variância devida aos resíduos da equação (SQRes), o que, em termos de cada ponto da série de dados, é representado pela equação (4), em que $c g l_{m}$ é a média amostral da série CGL e $c g l_{\text {est }}$ é a estimativa do CGL para cada ponto do tempo, conforme o modelo de regressão linear simples:

$$
S Q T=S Q \operatorname{Re} g+S Q \operatorname{Re} s=\sum_{t=1}^{T}\left(c g l_{t}-c g l_{m}\right)^{2}=\sum_{t=1}^{T}\left(c g l_{e s t}-c g l_{m}\right)^{2}+\sum_{t=1}^{T}\left(e_{e s t}\right)^{2}
$$

Conhecidas as fontes de variação e os graus de liberdade presentes em cada termo da equação (4), pode-se estabelecer a tabela ANOVA, Tabela 2, cujo F calculado possibilita avaliar a significância estatística dos coeficientes da equação (3) e, em especial, sua tendência temporal linear. 
Tabela 2. Análise de variância (ANOVA)

\begin{tabular}{cccc}
\hline $\begin{array}{c}\text { Fonte } \\
(\mathrm{A})\end{array}$ & $\begin{array}{c}\text { Graus de Liberdade } \\
(\mathrm{B})\end{array}$ & $\begin{array}{c}\text { Quadrado Médio }= \\
(\mathrm{A}) /(\mathrm{B})\end{array}$ & F calculado (Fcalc) \\
\hline & & & Fcalc $=$ \\
SQReg & 1 & SQReg/1 = QMReg & QMReg/QMRes \\
SQRes & $(\mathrm{n}-2)$ & SQRes $/(\mathrm{n}-2)=$ QMRes & \\
SQT & $(\mathrm{n}-1)$ & SQT $/(\mathrm{n}-1)$ & \\
\hline
\end{tabular}

Fonte: Elaborado pelo autor com base em Sartoris (2003).

Um terceiro instrumento de análise é aquele proposto em Crocco et al. (2006), o índice de Hirschman-Herfindahl modificado (HHm). Para os propósitos deste estudo, ele pode ser interpretado como a demanda líquida especificamente associada aos produtos agropecuários no âmbito das transações comerciais com a Índia e está apresentado na equação (5) a seguir.

$$
H H m_{i j}=\left(X_{i j} / X_{i^{*}}\right)-\left(X_{*_{j}} / X_{* *}\right)
$$

Esse índice supre parcialmente uma limitação intrínseca do CGL e do QL, que se refere ao fato de eles não selecionarem o grau de diversidade econômica da pauta agropecuária exportada pelo Brasil. Como se pode notar, o HHm traduz os efeitos líquidos (devidos à pauta agropecuária brasileira exportada) do fluxo comercial Brasil-Índia, no caso.

No HHm, a importância relativa de um país $j$ para o grupo $i$ de exportações agropecuárias brasileiras é descontada pela importância relativa do mesmo país para todos os bens (agropecuário e não agropecuários) exportados àquele destino. Com essa ferramenta adicional, obtêm-se informações desagregadas sobre se um dado comprador é - em termos líquidos - relativamente demandante de um grupo $i$ de exportações agropecuárias brasileiras.

Assim, respeitando o conjunto de produtos estabelecido pela Tabela 1, em linha com os detalhamentos metodológicos, o HHm e o QL serão calculados por grupo de produtos em agregação SH02. Já o CGL será aferido para o total das exportações agropecuárias brasileiras à Índia, em cada ano da série de dados disponíveis de 1989 a 2015.

\section{RESULTADOS E DISCUSSÃO}

Este tópico se subdivide em duas partes. A subseção 4.1 traz os resultados do QL, do CGL e do cálculo do teste F. Já a subseção 4.2 apresenta os valores correspondentes ao índice de Hirschman-Herfindahl modificado (HHm) e a discussão de resultados a ele associados. 


\section{Exportações agropecuárias brasileiras com destino à Índia}

Um primeiro passo de análise se relaciona com a participação da Índia nas exportações brasileiras. De acordo com a Figura 3, seja no âmbito das exportações agropecuárias ou no das exportações não agropecuárias, é diminuta a parcela devida à Índia, em geral abaixo do patamar de 3\% das receitas totais de exportações em ambos os casos. Assim, há espaço para o crescimento da parcela indiana nas compras de bens agropecuários brasileiros.

Comparativamente, observa-se maior oscilação da participação da Índia nas exportações brasileiras de bens agropecuários, com picos registrados em 1994, 1999, 2005 e 2009. O próprio coeficiente de variação foi da ordem de 0,92 para a participação da Índia nas exportações de bens agropecuários brasileiros, contra 0,78 para a participação da Índia nas exportações de itens não agropecuários exportados pelo Brasil.

Dois fatores podem explicar essa oscilação. Em primeiro plano, o fato de grandes produtores agrícolas como Estados Unidos, União Europeia, Canadá e Rússia estarem mais bem situados que o Brasil em termos da posição geográfica indiana, o que, em certos momentos, torna a oferta brasileira subsidiária no suprimento das importações feitas pela Índia.

Além disso, a oferta agropecuária interna da Índia está sujeita a inúmeros instrumentos de apoio interno (WTO, 2015), como subsídios à produção e à comercialização, suporte de preços e medidas tarifárias e não tarifárias de proteção. Esses mecanismos são articulados no Plano Agrícola Quinquenal e variam conforme o entendimento das autoridades indianas, dentro das margens permitidas pelos acordos comerciais de que a Índia é signatária.

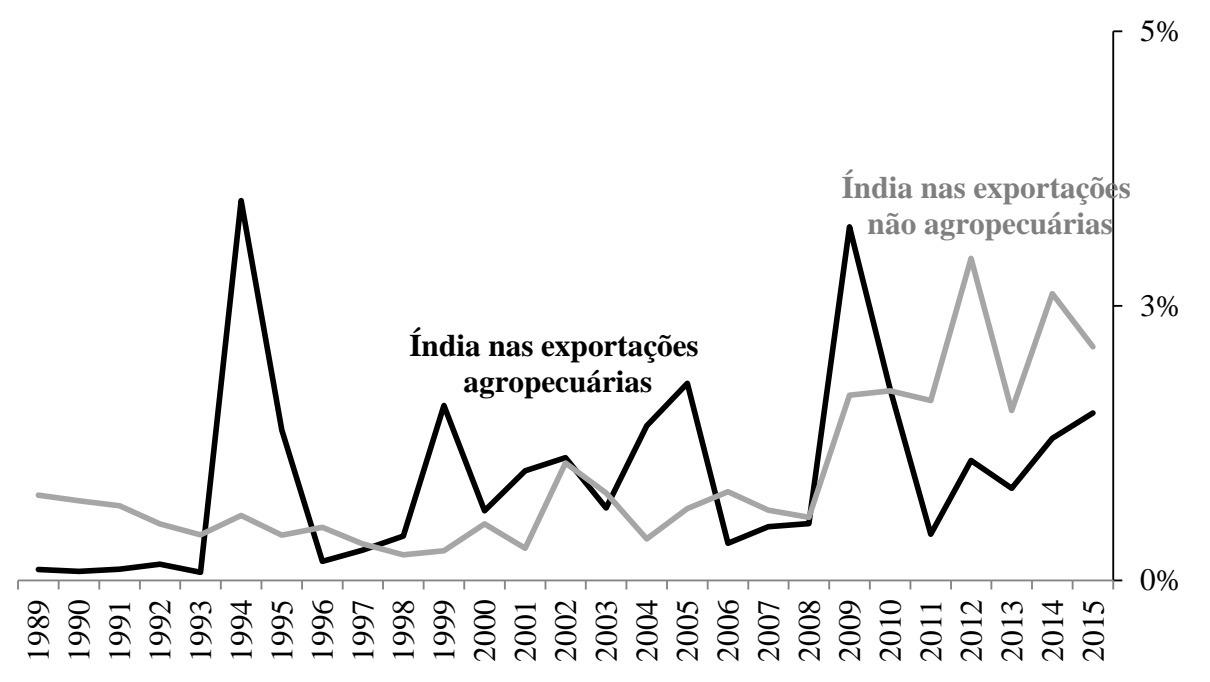

Figura 3. Participação da Índia nas exportações brasileiras, 1989-2015.

Fonte: Elaborado pelo autor com base em dados de BRASIL (2016b). 
Especificamente para o cálculo do CGL Índia, é importante frisar que ele tomou por base a participação dos diferentes grupos de produtos nas exportações agropecuárias brasileiras totais entre 1989 e 2015. Isto é, para os propósitos de cálculo do QL e do CGL, cotejou-se o perfil de exportações agropecuárias do Brasil para a Índia com o perfil das exportações agropecuárias do Brasil para o Mundo. Nesses termos, os procedimentos operacionais para medição do QL e do CGL tomaram como dada a seguinte distribuição de comércio nas exportações agropecuárias brasileiras totais para o Mundo, conforme a Tabela 3.

Na Tabela 3, os cinco principais grupos de bens agropecuários exportados pelo Brasil para o Mundo responderam, em média, por $66 \%$ das divisas de exportações auferidas pelo país em vendas de produtos agropecuários.

Observa-se também que os grupamentos líderes (sementes e oleaginosas, carnes e miudezas) são, em regra, produtos com baixo grau de processamento. Açúcares e confeitaria e café e mates já são produtos historicamente exportados pelo país. Uma terceira observação é que itens com algum grau de processamento exibiram proporcionalmente menor importância. É o caso das preparações (de hortícolas, carnes, cacau e cereais, alimentícias), manufaturados de tabaco e bebidas e vinagres.

Como estabelecido na metodologia, o cálculo do QL precede o do CGL em termos operacionais. Assim, a Tabela 4 informa o QL para os grupos de produtos agropecuários brasileiros exportados para a Índia entre 1989 e 2015. 
Tabela 3. Participação dos grupos de produtos nas exportações agropecuárias brasileiras totais, média do período 1989-2015.

\begin{tabular}{|c|c|c|c|}
\hline Grupo de produto (SH2) & Part. \% & Grupo de produto (SH2) & Part. \% \\
\hline Sementes e oleaginosas (12) & $16,09 \%$ & $\begin{array}{l}\text { Óleos essenciais e resinoides } \\
\text { (33) }\end{array}$ & $0,39 \%$ \\
\hline Carnes e miudezas (02) & $14,01 \%$ & Leite e laticínios (04) & $0,35 \%$ \\
\hline $\begin{array}{l}\text { Resíduos de ind. alimentares } \\
\text { (23) }\end{array}$ & $12,97 \%$ & Animais vivos (01) & $0,30 \%$ \\
\hline Açúcares e confeitaria (17) & $11,96 \%$ & Preparações de cereais (19) & $0,27 \%$ \\
\hline Café e mates (09) & $11,04 \%$ & Gomas e resinas vegetais (13) & $0,16 \%$ \\
\hline Preparações de hortícolas (20) & $6,93 \%$ & Produtos hortícolas (07) & $0,08 \%$ \\
\hline Tabaco e manufaturados (24) & $6,39 \%$ & Malte, amidos e féculas (11) & $0,08 \%$ \\
\hline Óleos anir & $4,58 \%$ & Plantas vivas e floricultura (06) & $0,08 \%$ \\
\hline $\begin{array}{l}\text { Preparações de carnes e peixes } \\
\text { (16) }\end{array}$ & $2,40 \%$ & $\begin{array}{l}\text { Lã e pelos finos ou grosseiros } \\
\text { (51) }\end{array}$ & $0,047 \%$ \\
\hline Cereais (10) & $2,32 \%$ & Seda (50) & $0,037 \%$ \\
\hline Preparações alimentícias (21) & $2,25 \%$ & $\begin{array}{l}\text { Produtos químicos orgânicos } \\
\text { (29) }\end{array}$ & $0,033 \%$ \\
\hline Frutas (08) & $1,93 \%$ & Matérias para entrançar (14) & $0,023 \%$ \\
\hline Bebidas e vinagres (22) & $1,73 \%$ & Peles e couros (41) & $0,023 \%$ \\
\hline Cacau e preparações (18) & $1,50 \%$ & $\begin{array}{l}\text { Outras fibras têxteis vegetais } \\
\text { (53) }\end{array}$ & $0,001 \%$ \\
\hline Algodão (52) & $0,99 \%$ & $\begin{array}{l}\text { Produtos diversos de ind. quím. } \\
\text { (38) }\end{array}$ & $0,0007 \%$ \\
\hline $\begin{array}{l}\text { Outros itens de origem animal } \\
(05)\end{array}$ & $0,55 \%$ & Peleteria e suas obras (43) & $0,0005 \%$ \\
\hline $\begin{array}{l}\text { Matérias albuminoides e colas } \\
\text { (35) }\end{array}$ & $0,48 \%$ & Produtos farmacêuticos (30) & $0,000001 \%$ \\
\hline
\end{tabular}

Fonte: Elaborado pelo autor com base em dados de BRASIL (2016b).

Para uma melhor compreensão, os valores são apresentados em termos médios para subperíodos relevantes, ou seja, 1989-2015 (toda a série), 1989-1994 (antes do Plano Real), 1994-2008 (entre o Plano Real e a crise econômica mundial iniciada nos Estados Unidos) e 2008-2015 (pós-crise econômica mundial). Como o último subperíodo é o mais recente, os dados estão ordenados em ordem decrescente de acordo com este subperíodo.

Somente três grupos de bens tiveram QL superior à unidade em todos os recortes temporais, isto é, são produtos em que a demanda indiana é particularmente focada. São eles os óleos animais ou vegetais, os açúcares e confeitaria e as gomas e resinas vegetais.

Ao mesmo tempo, óleos essenciais e resinoides e bebidas e vinagres destacam-se no subperíodo pós-1994 bem como na média do período todo. Este é um dado particularmente alvissareiro, por se referir a itens já processados e com algum nível de agregação de valor.

Por certo, a estabilização inflacionária brasileira após 1994 alterou o padrão de demanda interna por alimentos no Brasil, com reflexos não só Revista de Economia e Agronegócio - REA | V. 15 | N. 2 | 2017 | pág. 212 
na disponibilidade de bens alimentícios exportáveis, como também no nível de agregação de valor entre os segmentos agropecuário, agroindustrial e de comercialização.

Tabela 4. QL por grupos de produtos, subperíodos selecionados, 19892015.

\begin{tabular}{lllll}
\hline QL por grupos de produtos & $1989-2015$ & $1989-1994$ & $1994-2008$ & $2008-2015$ \\
\hline Produtos hortícolas (07) & 4,010 & 0,000 & 0,252 & 13,063 \\
Óleos animais ou vegetais (15) & 11,267 & 1,926 & 15,722 & 8,628 \\
Açúcares e confeitaria (17) & 3,456 & 4,684 & 4,657 & 3,103 \\
Gomas e resinas vegetais (13) & 11,358 & 32,007 & 7,105 & 2,575 \\
Óleos essenciais e resinoides (33) & 1,734 & 0,632 & 1,958 & 2,162 \\
Bebidas e vinagres (22) & 2,005 & 0,000 & 3,021 & 1,389 \\
Lã e pelos finos ou grosseiros (51) & 0,649 & 0,217 & 0,986 & 0,806 \\
Produtos diversos de ind. quím. (38) & 0,181 & 0,000 & 0,325 & 0,609 \\
Plantas vivas e floricultura (06) & 0,183 & 0,000 & 0,043 & 0,550 \\
Produtos químicos orgânicos (29) & 3,325 & 1,223 & 5,388 & 0,389 \\
Matérias albuminoides e colas (35) & 0,098 & 0,005 & 0,105 & 0,243 \\
Peles e couros (41) & 2,040 & 1,379 & 3,020 & 0,194 \\
Cereais (10) & 0,085 & 0,000 & 0,148 & 0,178 \\
Animais vivos (01) & 0,056 & 0,000 & 0,060 & 0,170 \\
Algodão (52) & 2,856 & 0,000 & 5,104 & 0,102 \\
Cacau e preparações (18) & 0,070 & 0,000 & 0,082 & 0,087 \\
Preparações alimentícias (21) & 0,075 & 0,001 & 0,116 & 0,044 \\
Preparações de hortícolas (20) & 0,032 & 0,000 & 0,044 & 0,041 \\
Tabaco e manufaturados (24) & 0,093 & 0,301 & 0,032 & 0,035 \\
Frutas (08) & 0,126 & 0,407 & 0,054 & 0,034 \\
Café e mates (09) & 0,024 & 0,000 & 0,031 & 0,030 \\
Resíduos de ind. alimentares (23) & 0,005 & 0,000 & 0,004 & 0,010 \\
Malte, amidos e féculas (11) & 0,003 & 0,000 & 0,003 & 0,007 \\
Leite e laticínios (04) & 0,005 & 0,017 & 0,003 & 0,006 \\
Preparações de cereais (19) & 0,012 & 0,000 & 0,019 & 0,005 \\
Outros itens de origem animal (05) & 0,002 & 0,000 & 0,002 & 0,005 \\
Sementes e oleaginosas (12) & 0,001 & 0,001 & 0,001 & 0,001 \\
Seda (50) & 0,560 & 0,946 & 0,912 & 0,000 \\
Matérias para entrançar (14) & 0,000 & 0,000 & 0,000 & 0,000 \\
Carnes e miudezas (02) & 0,000 & 0,001 & 0,000 & 0,000 \\
Preparações de carnes e peixes (16) & 0,000 & 0,001 & 0,000 & 0,000 \\
Outras fibras têxteis vegetais (53) & 0,000 & 0,000 & 0,000 & 0,000 \\
Peleteria e suas obras (43) & 0,000 & 0,000 & 0,000 & 0,000 \\
Produtos farmacêuticos (30) & 0,000 & 0,000 & 0,000 & 0,000 \\
\hline \multicolumn{1}{|c}{ Fonte: Resun }
\end{tabular}

Fonte: Resultados da pesquisa. 
A Tabela 5 apresenta os dados obtidos para o CGL Índia, que apontam, na média, uma tênue concentração das exportações agropecuárias brasileiras em torno dos mercados indianos. Ao mesmo tempo, pode-se observar a variável média [CGL ${ }_{t} \mathrm{CGL}_{t 0}$ ], resultante da média dos CGL entre $t$ e $t_{0}$. Definida assim, para 1989 é o valor do CGL no próprio ano, para 1990 é a média entre os valores do coeficiente para 1989 e 1990, para 1991 é a média dos valores do coeficiente para 1989, 1990 e 1991, e assim por diante, para todos os anos mensurados.

Nesse caso, ressalta-se o fato de a variável média [CGL ${ }_{t} ; \mathrm{CGL}_{t 0}$ ] ter transitado de valores negativos (desconcentração) no início da década de 1990 para valores exclusivamente positivos a partir de 1998. Este fato sugere uma sutil tendência de longo prazo a favor das importações agropecuárias oriundas do Brasil.

Tabela 5. CGL e média [CGL $\left.{ }_{t} ; \mathrm{CGL}_{t 0}\right]$ das exportações agropecuárias Brasil-Índia, 1989-2015.

\begin{tabular}{lccccc}
\hline & CGL & Média [CGL $\left.{ }_{t} ; C^{\prime} L_{t 0}\right]$ & & CGL & Média [CGL [CGL $_{t}$ ] \\
\hline 1989 & $-0,221$ & $-0,221$ & 2003 & 0,030 & 0,105 \\
1990 & $-0,231$ & $-0,226$ & 2004 & 0,461 & 0,127 \\
1991 & $-0,197$ & $-0,216$ & 2005 & 0,345 & 0,140 \\
1992 & $-0,147$ & $-0,199$ & 2006 & $-0,101$ & 0,127 \\
1993 & $-0,185$ & $-0,196$ & 2007 & 0,007 & 0,120 \\
1994 & 0,609 & $-0,062$ & 2008 & 0,048 & 0,117 \\
1995 & 0,427 & 0,008 & 2009 & 0,306 & 0,126 \\
1996 & $-0,134$ & $-0,010$ & 2010 & 0,078 & 0,124 \\
1997 & 0,036 & $-0,005$ & 2011 & $-0,182$ & 0,110 \\
1998 & 0,238 & 0,020 & 2012 & $-0,133$ & 0,100 \\
1999 & 0,599 & 0,072 & 2013 & $-0,055$ & 0,094 \\
2000 & 0,224 & 0,085 & 2014 & $-0,071$ & 0,088 \\
2001 & 0,441 & 0,112 & 2015 & 0,034 & 0,086 \\
2002 & 0,085 & 0,110 & Média & & 0,086 \\
\hline
\end{tabular}

Fonte: Resultados da pesquisa.

Por sua vez, o valor calculado para o teste $\mathrm{F}$ implica rejeitar a tendência estimada em $1 \%, 5 \%$ ou $10 \%$ de significância estatística. Ou seja, não é factível afirmar que a inclinação devida ao tempo para explicar o CGL seja diferente de 0 ao longo do intervalo temporal avaliado. Os dados para o teste F são apresentados na Tabela 6.

Dada a natureza dos dados do CGL para a Índia, uma abordagem alternativa consiste em calcular a reta de tendência linear contra o tempo para a média acumulada da série, média [CGL; $\left.\mathrm{CGL}_{t 0}\right]$ da Tabela 5 . Neste caso, o valor calculado para o teste $\mathrm{F}(50,58)$ implica aceitar a tendência estimada em $1 \%$ de significância estatística. Isto é, pode-se afirmar que a Revista de Economia e Agronegócio - REA | V. 15 | N. 2 | 2017 | pág. 214 
inclinação linear devida ao tempo para explicar a média acumulada da série CGL seja diferente de 0 ao longo do intervalo temporal empregado na análise. A Figura 4 informa os dados correspondentes.

Tabela 6. Teste F e ANOVA para a tendência no tempo do CGL, 19892015.

\begin{tabular}{ccccc}
\hline \multirow{2}{*}{ Fonte } & $\begin{array}{c}\text { Graus de } \\
\text { liberdade }\end{array}$ & $\begin{array}{c}\text { Soma dos Quadrados } \\
(\mathrm{SQ})\end{array}$ & $\begin{array}{c}\text { Quadrado Médio } \\
(\mathrm{QM})\end{array}$ & $\mathrm{F}$ \\
\hline Regressão & 1 & 0,0003 & 0,0003 & 0,005 \\
Resíduo & 25 & 1,7435 & 0,0697 & \\
Total & 26 & 1,7439 & 0,0671 & \\
\hline
\end{tabular}

Fonte: Resultados da pesquisa.

Esta informação sugere que, ao longo do tempo, cumulativamente e no longo prazo, houve uma sutil tendência de crescimento do CGL em bens agropecuários exportados em torno do mercado indiano. Entretanto, a estabilização deste processo a contar de 2005 exige cautela ao analisar a atração das exportações agropecuárias brasileiras em torno daquele país.

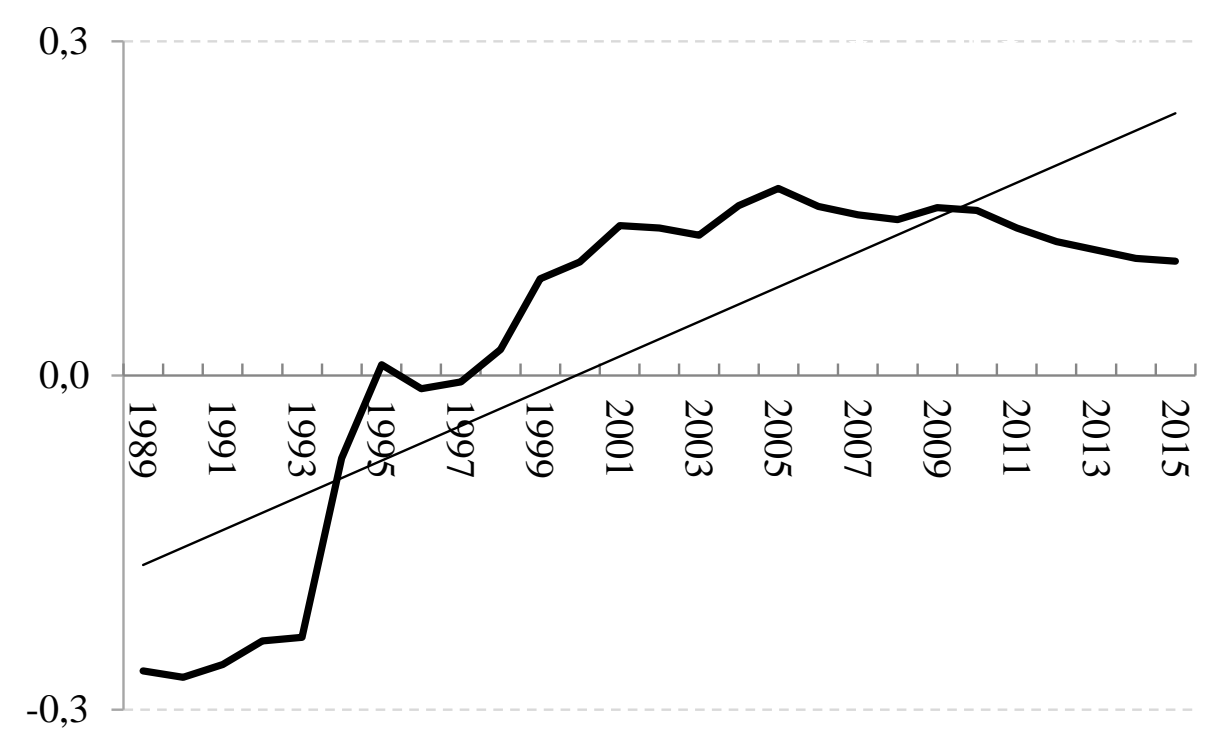

Figura 4. Média [CGL $L_{t} ; \mathrm{CGL}_{t 0}$ ] e reta estimada de tendência no tempo, 1989-2015.

Fonte: Resultados da pesquisa.

Vários fatores podem estar por trás desse comportamento. Santo, Lima e Souza (2012) enfatizam as tarifas médias relativamente altas praticadas pela Índia e o mercado relativamente fechado para as exportações 
agrícolas brasileiras, inclusive pela presença de questões fitossanitárias (WTO, 2015).

Sobre este aspecto, levantaram-se dados das tarifas de importação cobradas pela Índia em bens agropecuários. Os dados foram extraídos do consórcio WTO-IDB (2017) e obtidos por meio do World Integrated Trade Solution - World Bank (WITS/WB), que congrega bases de comércio e tarifas da UNCTAD, ITC, WORLD BANK, UNSD e WTO.

Tomados em conta somente os bens agropecuários, a tarifa geral vigente para parceiros comerciais (nação mais favorecida) da Índia está, na média de 2015 , em $36,27 \%$, com pico de $150 \%$, o que sugere a existência de um amplo raio de proteção comercial entre a tarifa média e os itens de maior proteção tarifária. Já no âmbito dos países de menor desenvolvimento, há preferências comerciais que se traduzem numa tarifa média de 13,28\% e pico tarifário também de $150 \%$. Ou seja, nessas preferências comerciais, o acesso geral é mais fácil, mas ainda assim vigoram itens com elevada proteção específica.

No caso do acesso brasileiro ao mercado indiano, há um acordo de preferências comerciais Mercosul-Índia, dentro do qual há linhas tarifárias contempladas (BRASIL, 2017). Todavia, é reduzida a cobertura da oferta de redução tarifária da Índia em bens agropecuários, de modo que somente 25 produtos agropecuários estão citados, algo como 10\% das linhas tarifárias da oferta indiana ao Mercosul, ou 2\% das linhas tarifárias agropecuárias impostas aos parceiros gerais da Índia (nação mais favorecida). Inclusive, a única quota tarifária oferecida ao Mercosul seria no âmbito da NCM 1507100 (óleo bruto de semente de soja, degomado ou não), exclusiva de acesso ao Paraguai.

Isto posto, no contexto das negociações Mercosul-Índia, as exportações agropecuárias brasileiras ao mercado indiano desfrutam de pouco alívio tarifário.

Resta ainda analisar, no âmbito das exportações agropecuárias BrasilÍndia, em quais produtos tem se concentrado a demanda da Índia por bens agropecuários. Ainda que, no agregado da pauta de exportações agropecuárias brasileiras à Índia, a concentração seja sutil e tenha se estabilizado no tempo, a avaliação de grupos de bens é necessária.

\section{Índice de Hirschman-Herfindahl modificado (HHm)}

Os valores médios calculados para o índice HHm no período 1989-2015 denotam que a Índia é um mercado destacável no caso das exportações de nove grupos de bens definidos como agropecuários pela WTO (2011): óleos animais ou vegetais, produtos hortícolas, gomas e resinas vegetais, açúcares e confeitaria, produtos químicos orgânicos, bebidas e vinagres, algodão, óleos essenciais e resinoides e peles e couros. 
Os dados da Tabela 7 ilustram este argumento.

Tabela 7. HHm médio das exportações agropecuárias brasileiras para a Índia, 1989-2015

\begin{tabular}{|c|c|c|c|}
\hline Grupo de produto (SH2) & $\begin{array}{l}\text { HHm } \\
\text { Médio }\end{array}$ & Grupo de produto (SH2) & $\begin{array}{l}\text { HHm } \\
\text { Médio }\end{array}$ \\
\hline Óleos animais ou vegetais (15) & 0,0835 & Animais vivos (01) & $-0,0087$ \\
\hline Produtos hortícolas (07) & 0,0647 & Tabaco e manufaturados (24) & $-0,0087$ \\
\hline Gomas e resinas vegetais (13) & 0,0528 & Preparações alimentícias (21) & $-0,0088$ \\
\hline Açúcares e confeitaria (17) & 0,0324 & Cereais (10) & $-0,0088$ \\
\hline Produtos químicos orgânicos (29) & 0,0103 & Preparações de hortícolas (20) & $-0,0091$ \\
\hline Bebidas e vinagres (22) & 0,0098 & Café e mates (09) & $-0,0091$ \\
\hline Algodão (52) & 0,0072 & Preparações de cereais (19) & $-0,0093$ \\
\hline Óleos essenciais e resinoides (33) & 0,0064 & $\begin{array}{l}\text { Resíduos de ind. alimentares } \\
(23)\end{array}$ & $-0,0093$ \\
\hline Peles e couros (41) & 0,0042 & Leite e laticínios (04) & $-0,0093$ \\
\hline Lã e pelos finos ou grosseiros (51) & $-0,0038$ & $\begin{array}{l}\text { Outros itens de origem animal } \\
(05)\end{array}$ & $-0,0093$ \\
\hline Produtos farmacêuticos (30) & $-0,0046$ & Malte, amidos e féculas (11) & $-0,0093$ \\
\hline Seda (50) & $-0,0048$ & Sementes e oleaginosos (12) & $-0,0093$ \\
\hline Plantas vivas e floricultura (06) & $-0,0065$ & Carnes e miudezas (02) & $-0,0093$ \\
\hline $\begin{array}{l}\text { Matérias albuminoides e colas } \\
\text { (35) }\end{array}$ & $-0,0083$ & Matérias para entrançar (14) & $-0,0093$ \\
\hline $\begin{array}{l}\text { Produtos diversos de ind. quím. } \\
\text { (38) }\end{array}$ & $-0,0083$ & $\begin{array}{l}\text { Preparações de carnes e peixes } \\
\text { (16) }\end{array}$ & $-0,0093$ \\
\hline Cacau e preparações (18) & $-0,0086$ & $\begin{array}{l}\text { Outras fibras têxteis vegetais } \\
(53)\end{array}$ & $-0,0093$ \\
\hline Frutas $(08)$ & $-0,0086$ & Peleteria e suas obras (43) & $-0,0099$ \\
\hline
\end{tabular}

Fonte: Resultados da pesquisa.

Destaque específico deve ser dado a três grupos de produtos que lideram a demanda líquida oriunda da Índia: os óleos animais ou vegetais, os produtos hortícolas e as gomas e resinas vegetais.

De menor valor médio, um segundo grupamento que deve ser mencionado contempla os açúcares e confeitaria e os produtos químicos orgânicos. Este último caso deve ser balizado pelo condicionante de que seus resultados são afetados por um número reduzido de alíneas consideradas agrícolas no capítulo 29 (2905.43 e 2905.44).

O diminuto número de produtos com demanda líquida relevante nas exportações agropecuárias brasileiras à Índia pode ensejar estudos específicos, uma vez que a demanda indiana pode estar caminhando para uma especialização no detalhe do processo comercial, não para o conjunto da pauta agropecuária negociada pelo Brasil. 
De outra sorte, quando se observam os grupos de bens com $\mathrm{HHm}$ negativo, há entre eles itens nos quais a tarifa média indiana é igual ou superior a $30 \%(\mathrm{WTO}, 2015)$. É o caso das frutas $(35,05 \%)$, tabaco e manufaturados $(31,31 \%)$, preparações alimentícias $(64,29 \%)$, cereais $(30,54 \%)$, café e mates $(60,94 \%)$, malte, amidos e féculas $(31,71 \%)$, matérias para entrançar $(30 \%)$ e preparações de carnes e peixes $(42,73 \%)$. Esse ponto reforça o argumento de Santo, Lima e Souza (2012), de que em muitos aspectos a Índia é ainda um mercado protegido, de modo que as negociações diplomáticas devem contemplá-la como prioridade.

Além do recorte de valor médio do $\mathrm{HHm}$, uma análise complementar diz respeito à duração ou proporção de anos em que cada grupo de produto foi objeto de um efeito líquido positivo da demanda indiana, conforme assinalado na Tabela 8 .

Tabela 8. Proporção de anos com HHm positivo no intervalo 1989-2015

\begin{tabular}{|c|c|c|c|}
\hline Grupo de produto (SH2) & $\mathrm{HHm}>0$ & Grupo de produto (SH2) & $\mathrm{HHm}>0$ \\
\hline $\begin{array}{l}\text { Óleos animais ou vegetais } \\
\text { (15) }\end{array}$ & $96 \%$ & Carnes e miudezas (02) & $0 \%$ \\
\hline Gomas e resinas vegetais (13) & $89 \%$ & $\begin{array}{l}\text { Resíduos de ind. alimentares } \\
(23)\end{array}$ & $0 \%$ \\
\hline $\begin{array}{l}\text { Óleos essenciais e resinoides } \\
\text { (33) }\end{array}$ & $74 \%$ & Café e mates (09) & $0 \%$ \\
\hline $\begin{array}{l}\text { Produtos químicos orgânicos } \\
\text { (29) }\end{array}$ & $59 \%$ & Preparações de hortícolas (20) & $0 \%$ \\
\hline Açúcares e confeitaria (17) & $56 \%$ & $\begin{array}{l}\text { Preparações de carnes e peixes } \\
\text { (16) }\end{array}$ & $0 \%$ \\
\hline Produtos hortícolas (07) & $33 \%$ & Preparações alimentícias (21) & $0 \%$ \\
\hline Bebidas e vinagres (22) & $30 \%$ & Cacau e preparações (18) & $0 \%$ \\
\hline $\begin{array}{l}\text { Lã e pelos finos ou grosseiros } \\
\text { (51) }\end{array}$ & $19 \%$ & $\begin{array}{l}\text { Outros itens de origem animal } \\
(05)\end{array}$ & $0 \%$ \\
\hline Algodão (52) & $15 \%$ & $\begin{array}{l}\text { Matérias albuminoides e colas } \\
\text { (35) }\end{array}$ & $0 \%$ \\
\hline Seda (50) & $15 \%$ & Leite e laticínios (04) & $0 \%$ \\
\hline Peles e couros (41) & $15 \%$ & Animais vivos (01) & $0 \%$ \\
\hline $\begin{array}{l}\text { Plantas vivas e floricultura } \\
(06)\end{array}$ & $7 \%$ & Preparações de cereais (19) & $0 \%$ \\
\hline Tabaco e manufaturados (24) & $4 \%$ & Malte, amidos e féculas (11) & $0 \%$ \\
\hline Cereais (10) & $4 \%$ & Matérias para entrançar (14) & $0 \%$ \\
\hline Frutas (08) & $4 \%$ & $\begin{array}{l}\text { Outras fibras têxteis vegetais } \\
(53)\end{array}$ & $0 \%$ \\
\hline $\begin{array}{l}\text { Produtos diversos de ind. } \\
\text { quím. (38) }\end{array}$ & $4 \%$ & Peleteria e suas obras (43) & $0 \%$ \\
\hline Sementes e oleaginosos (12) & $0 \%$ & Produtos farmacêuticos (30) & $0 \%$ \\
\hline
\end{tabular}

Fonte: Resultados da pesquisa. 
Somente óleos animais ou vegetais, gomas e resinas vegetais, óleos essenciais e resinoides, produtos químicos orgânicos e açúcares e confeitaria registraram $\mathrm{HHm}$ positivo em $50 \%$ ou mais dos anos amostrados. Além da questão tarifária descrita anteriormente para alguns grupos de bens, há também as medidas não tarifárias, principalmente restrições à importação por conta de medidas sanitárias, importações sujeitas a licenciamento ou somente permitidas a empresas estatais indianas.

De acordo com a WTO (2015), limitadores dessa natureza aplicam-se, por exemplo, a óleos animais, animais vivos, produtos de origem vegetal em geral, cereais e lácteos. Na mesma linha, Santo, Lima e Souza (2012) já haviam enfatizado que, ainda que exista um acordo de preferência comercial Mercosul-Índia, os entraves sanitários são efetivos e amplificados pelo complexo sistema indiano de comércio.

\section{CONSIDERAÇÕES FINAIS}

A parcela indiana nas exportações agropecuárias brasileiras é modesta e o país representa um mercado ainda potencial para os produtos agropecuários do Brasil. Neste âmbito, os resultados da pesquisa evidenciaram leve aumento de concentração dos produtos brasileiros em torno do mercado da Índia até 2005, com estabilização do fenômeno desde então.

Em termos de produtos, os resultados do QL enfatizaram as aquisições indianas nos grupos de óleos animais ou vegetais, açúcares e confeitaria e gomas e resinas vegetais. Ainda sob este prisma, óleos essenciais e resinoides e bebidas e vinagres destacam-se, particularmente no subperíodo pós-1994.

Já a demanda líquida indiana por bens agropecuários mapeou os mesmos grupamentos, acrescentando os casos dos produtos hortícolas, produtos químicos orgânicos, algodão e peles e couros. Os três últimos grupamentos podem representar uma vulnerabilidade para as exportações agropecuárias brasileiras, dado o reduzido número de alíneas comerciais envolvidas.

Para alguns grupos de bens em que o Brasil é competitivo internacionalmente, como café e mates, preparações de carnes, tabaco e manufaturados e preparações alimentícias, o aparato tarifário indiano não pode ser subestimado em termos de uma limitação de acesso àquele mercado, do mesmo modo que a incidência de inúmeras políticas agrícolas domésticas. A esses fatores, soma-se a restrição da distância e de regulações sanitárias em produtos de origem animal ou vegetal, caso das frutas, leite e laticínios e carnes e miudezas. 
Em que pese haver um acordo de comércio preferencial Mercosul-Índia, ele é pouco abrangente em termos do acesso de produtos agropecuários do Mercosul àquele país, ao menos por enquanto. Dada a proximidade de outros grandes produtores de alimentos do mercado da Índia, o aprofundamento das negociações do citado acordo é, sem dúvida, estratégico.

\section{REFERÊNCIAS}

BARROS, José Roberto Mendonça de; BARROS, Alexandre Lahóz Mendonça. A geração de conhecimento e o sucesso do agronegócio brasileiro. Revista de Política Agrícola, Brasília, v.14, n. 4, p. 5-14, out./dez. 2005.

BONELLI, Régis; MALAN, Pedro Sampaio. Os limites do possível: notas sobre o balanço de pagamentos e indústria nos anos 70. Pesquisa e Planejamento Econômico, Rio de Janeiro, v. 6, n. 2, p. 353-406, ago. 1976.

BRASIL. Ministério da Indústria, Comércio Exterior e Serviços - MDIC. Correlação da NBM $x$ NCM - 1996. Brasília, 1996. Disponível em: < http://www.mdic.gov.br/arquivos/dwnl_1386353947.xls>. Acesso em: 01 jun. 2012.

BRASIL. Presidência da República. Ministro das Relações Exteriores defende o estreitamento das relações bilaterais. Brasil no BRICS. Brasília, 15 out. 2016a. Disponível em: <http://www2.planalto.gov.br/acompanheplanalto/noticias/2016/10/com-acordos-comercio-entre-brasil-e-indiapode-triplicar-em-poucos-anos-diz-serra>. Acesso em: 27 jun. 2017.

BRASIL. Ministério da Indústria, Comércio Exterior e Serviços - MDIC. Aliceweb. Brasília, 2016b. Disponível em: <http://aliceweb.desenvolvimento.gov.br/>. Acesso em: 30 mar. 2016.

BRASIL. Ministério da Indústria, Comércio Exterior e Serviços - MDIC. Mercosul - Índia - Ampliação do ACP Mercosul - Índia. Brasília, 2017. Disponível em: <http://www.mdic.gov.br/comercioexterior/negociacoes-internacionais/132-acordos-dos-quais-o-brasil-eparte/1831-acordos-mercosul-india >. Acesso em: 27 jun. 2017.

CÂMARA, Gilberto. et al. Modelling Land Use Change in Brazil: 2000-2050 A Report by the REDD-PAC project. São José dos Campos: INPE; Brasília: IPEA; Luxemburgo: IIASA; Cambridge: UNEP-WCMC, 2015.

CROCCO, Marco Aurélio. et al. Metodologia de identificação de aglomerações produtivas locais. Nova Economia, Belo Horizonte, v. 16, n. 2, p. 211241, mai./ago. 2006. doi:10.1590/s0103-63512006000200001. 
DA MATA, Daniel Ferreira Gonçalves; FREITAS, Rogério Edivaldo. Produtos agropecuários: para quem exportar? Revista de Economia e Sociologia Rural, Brasília, v. 46, n. 2, p. 257-290, abr./jun. 2008. doi:10.1590/s0103-20032008000200001.

FONSECA, Henrique Veras de Paiva; XAVIER, Leonardo Ferraz; COSTA, Ecio de Farias. Análise das exportações de uvas frescas. Revista de Economia Agrícola, São Paulo, v. 57, n. 2, p. 81-98, jul./dez. 2010.

FREITAS, Rogério Edivaldo. Exportações agropecuárias brasileiras - os mercados dos EUA. Revista de Política Agrícola, Brasília, vol. 25, n. 4, p. 136151, out./dez. 2016.

FREITAS, Rogério Edivaldo; MENDONÇA, Marco Aurélio Alves de. Expansão Agrícola no Brasil e a Participação da Soja: 20 anos. Revista de Economia e Sociologia Rural, Brasília, v. 54, n. 3, p. 497-516, jul./set. 2016. doi:10.1590/1234-56781806-94790540306.

GUJARATI, Damodar. Basic Econometrics. Singapore: McGraw-Hill, 1995.

HADDAD, Paulo Roberto. Medidas de localização e de especialização. In: HADDAD, Paulo Roberto et al. (Org.). Economia regional: teorias e métodos de análise. Fortaleza: BNB-ETENE, 1989. p. 225-248.

KRUGMAN, Paul. Geography and trade. Cambridge: MIT Press, 1991.

LU, Zheng; FLEGG, A. Tony; DENG, Xiang. Regional specialization: a measure method and the trends in China. MPRA, n. 33867, nov. 2011. Disponível em: <http://mpra.ub.uni-muenchen.de/33867/>. Acesso em: 30 set. 2015.

NOGUEIRA, Antonio Carlos Lima. Perspectivas do agronegócio global e impactos no Brasil. Informações FIPE, São Paulo, n. 406, p. 3-5, jul. 2014.

REVEIU, Adriana Elena; DARDALA, Marian. Quantitative Methods for Identification of Regional Clusters in Romania. Journal of Applied Quantitative Methods, v. 6, n. 2, p. 1-11, jun. 2011.

RUAN, Jianqing; ZHANG, Xiaobo. "Flying geese" in China: The textile and apparel industry's pattern of migration. Journal of Asian Economics, v. 34, p. 79-91, out. 2014. doi:10.1016/j.asieco.2014.06.003.

SANTO, Benedito Rosa do Espírito. Brazil in the world dairy market. Revista de Política Agrícola, Brasília, v. 19, n.1, p. 63-70, jan./mar. 2010.

SANTO, Benedito Rosa do Espírito; LIMA, Márcio Luiz F. N. de; SOUZA, Cássio Bruno Sá de. Os vinte principais mercados para exportação agrícola no futuro. Revista de Política Agrícola, Brasília, v. 21, n. 1, p. 76-91, jan./mar. 2012. 
SARTORIS, Alexandre. Estatística e introdução à econometria. São Paulo: Saraiva, 2003.

SOUSA, Lucas Oliveira de. et al. Análise das intervenções nas exportações de açúcar bruto do Brasil para a Rússia, de 1997 a 2010. Revista de Política Agrícola, Brasília, v. 20, n. 3, p. 63-76, jul./ set. 2011.

SOUZA, Rodrigo da Silva. et al. Competividade dos principais produtos agropecuários do Brasil (vantagem comparativa revelada normalizada). Revista de Política Agrícola, Brasília, v. 21, n. 2, p. 64-71, abr./jun. 2012.

SUZIGAN, Wilson. et al. Coeficientes de Gini Locacionais - GL: aplicação à indústria de calçados do Estado de São Paulo. Nova Economia, Belo Horizonte, v. 13, n. 2, p. 39-60, jul./dez. 2003.

UNITED NATIONS. World Population Prospects: The 2017 Revision, Total Population - Both Sexes, Medium Variant. New York, 2017. Disponível em: <https://esa.un.org/unpd/wpp/Download/Standard/Population>.

Acesso em: 29 ago. 2017.

WORLD BANK - WB. World Bank national accounts data, and OECD National Accounts data files. Washington, DC, 2016. Disponível em: $<$ http://databank.worldbank.org/data/home.aspx >. Acesso em: 19 jul. 2016.

WORLD TRADE ORGANIZATION - WTO. Agreement on Agriculture. Washington, DC, 2011. Disponível em: <http://www.wto.org/english/docs_e/legal_e/14-ag.pdf >. Acesso em: 20 dez. 2011.

WORLD TRADE ORGANIZATION - WTO. Trade Policy Review - Report by The Secretariat - India - Revision. [s.1.], 2015. Disponível em: <https://www.wto.org/english/tratop_e/tpr_e/tp413_e.htm>. Acesso em: 27 jun. 2017.

WORLD TRADE ORGANIZATION/INTEGRATED DATA BASE (WTOIDB). World Integrated Trade Solution - WITS. [s.1.], 2017. Disponível em: <http://wits.worldbank.org/WITS/WITS/QuickQuery/FindTariff/Find Tariff.aspx?Page=FindATariff $>$. Acesso em: 27 jun. 2017.

YOKOTA, Paulo. Painel III: Impactos da mudança tecnológica do setor agropecuário brasileiro sobre o abastecimento. In: SEMINÁRIO SOBRE IMPACTOS DA MUDANÇA TECNOLÓGICA DO SETOR AGROPECUÁRIO NA ECONOMIA BRASILEIRA, 2001, Brasília. Anais... Brasília: Embrapa Informação Tecnológica - Embrapa-SEA, 2002. p. 203206. 


\section{ANEXO}

Este ponto do estudo informa os procedimentos utilizados, de modo a levar em conta a transição de códigos comerciais entre a Nomenclatura Brasileira de Mercadorias (NBM, 1989-1996) e a Nomenclatura Comum do Mercosul (NCM, 1996-2012), conforme a seguir:

1. O código SH 3823.60 = sorbitol (poliálcool, também chamado de glucitol) nep consta da lista do Acordo Agrícola, mas não foi localizado na NCM. De toda a sorte, a NCM 2905.44 já contempla o D-Glucitol (sorbitol) (poliálcool).

2. A NCM $3823.70=$ álcoois graxos industriais e outras misturas de álcoois primários alifáticos corresponde à NBM 1519.20, que NÃO pertence ao capítulo 15 na listagem da NCM. Logo, a NCM 3823.70 não foi incluída.

3. Dentre as alíneas 1603 , há duas alíneas NBM que não se referem a peixes, mas sim a carnes, e, portanto, foram incluídas no total agropecuário. São elas: NBM 1603000101 (extratos de carne) $\Leftrightarrow$ NCM 16030000 (extratos e sucos de carnes, de peixes, de crustáceos, etc.); e, NBM 1603000201 (sucos de carnes) $\Leftrightarrow$ NCM 16030000 (extratos e sucos de carnes, de peixes, de crustáceos, etc.). As respectivas NCM não foram incluídas por não separarem as carnes dos peixes e crustáceos. Já as alíneas 1604 e 1605 referem-se exclusivamente a peixes e/ou crustáceos; destarte, foram excluídas em todos os anos da série.

4. As NBM 2208100101, 2208100102, 2208100199, 2208109901, 2208109902, 2208109903, 2208109904, 2208109905, 2208109999 correspondem à NCM 21069010. Ambos os capítulos (21 e 22) pertencem integralmente ao Acordo Agrícola, e todas as alíneas foram incluídas.

5. A NBM 1301909900 (outras gomas, resinas, gomas-resinas e bálsamos naturais) corresponde à NCM 13019000. Ambos os itens pertencem integralmente ao Acordo Agrícola, e foram incluídos. 